\title{
SEASONAL DIFFERENCES IN SPATIAL SCALES OF CHLOROPHYLL-A CONCENTRATION IN LAKE TAIHU, CHINA
}

\author{
Ying Bao $^{\text {a }}$, Qingjiu Tian ${ }^{\mathrm{a},}$, Shaojie Sun ${ }^{\mathrm{a}}$, Hongwei Wei ${ }^{\mathrm{a}}$, Jia Tian ${ }^{\mathrm{b}}$ \\ ${ }^{a}$ International Institute for Earth System Science, Nanjing University, Nanjing 210093, China- \\ qiheye100@163.com,tianqj@nju.edu.cn,sunshaojie87@126.com,piaoxue.6416931@163.com \\ ${ }^{\mathrm{b}}$ School of Electronic Science and Engineering, Nanjing University, Nanjing 210093, China- tian-jia08@163.com
}

Commission VII, WG VII/5

KEY WORDS: Chlorophyll-a concentration, Scale Heterogeneity, Scale Error, Different Seasons

\begin{abstract}
:
Spatial distribution of chlorophyll-a (chla) concentration in Lake Taihu is non-uniform and seasonal variability. Chla concentration retrieval algorithms were separately established using measured data and remote sensing images (HJ-1 CCD and MODIS data) in October 2010, March 2011, and September 2011. Then parameters of semi- variance were calculated on the scale of $30 \mathrm{~m}, 250 \mathrm{~m}$ and $500 \mathrm{~m}$ for analyzing spatial heterogeneity in different seasons. Finally, based on the definitions of Lumped chla (chlaL) and Distributed chla (chlaD), seasonal model of chla concentration scale error was built. The results indicated that: spatial distribution of chla concentration in spring was more uniform. In summer and autumn, chla concentration in the north of the lake such as Meiliang Bay and Zhushan Bay was higher than that in the south of Lake Taihu. Chla concentration on different scales showed the similar structure in the same season, while it had different structure in different seasons. And inversion chla concentration from MODIS $500 \mathrm{~m}$ had a greater scale error. The spatial scale error changed with seasons. It was higher in summer and autumn than that in spring. The maximum relative error can achieve $23 \%$.
\end{abstract}

\section{INTRODUCTION}

Chlorophyll-a (chla) plays a significant role in water ecosystem. It is a basic indicator of lake eutrophication (Zhou et al., 2009). The change of its spatial distribution and concentration can influence the lake ecosystem. In recent decades, water quality remote sensing has become an effective way to monitor it. However, spatial heterogeneity could cause scale effect in the retrieval of chla concentration from multi-resolution remote sensing images (Bao et al., 2011). It brings scale error (Chen et al., 2010). And the error affects the retrieval accuracy and varies with seasons. Therefore, studying seasonal differences in spatial scales of chla concentration is useful for improvement of the retrieval accuracy.

Spatial scale effect and uncertainty based on remote sensing images had been studied domestic and abroad. Moran coefficient, Geary ration, coefficient of variation and variograms were the most commonly used methods for analyzing spatial heterogeneity (Zhang, 2008). Researches usually provided variogram function for studying spatial heterogeneity and spatial effect of water quality parameters. They found that spatial distribution of chla concentration exist structure (Xia et al., 2011; Liu et al., 2002). In addition, new methods such as hydrodynamic model, biological model were introduced to solve practical problem (Chen et al., 2010; Fragoso et al., 2008). Moreover, spatial scale uncertainty is also a hotspot in current studying (Zhang, 2008). Radiative transfer model, regressive model and fractal theory are popular methods for studying spatial errors and spatial scaling (Chen et al., 2006). But most methods for spatial uncertainties were based on vegetation. The work for water quality parameters has not been extensively researched. As there is no sensor for inland water quality remote sensing, land satellites and ocean colour satellite were used to estimate chla concentration (Zhou et al., 2009). Both of the data souses and spatial heterogeneity of chla concentration can affect the retrieval accuracy.

In this paper, Lake Taihu in the east of China was selected as the study area. Based on the chla concentration retrieval algorithm and the results of spatial effects, a model of spatial scale error was established for MODIS $500 \mathrm{~m}$. Then the paper analyzed seasonal results which were calculated in different spatial scales.

\section{STUDY AREA AND DATA PREPROCESS}

\subsection{Study Area}

Lake Taihu is one of the five largest freshwater lakes in China. The lake, situated in the southeast of the country $\left(30^{\circ} 55^{\prime} 40^{\prime \prime}\right.$ $31^{\circ} 32^{\prime} 58^{\prime \prime} \mathrm{N}, 30^{\circ} 55^{\prime} 40^{\prime \prime}-31^{\circ} 32^{\prime} 58^{\prime \prime} \mathrm{E}$ ), is a typical inland shallow lake with a water area of $2388 \mathrm{~km}^{2}$ (Tang et al., 2007; Zhang et al. 2011). Taihu Basin is located in Shanghai, Jiangsu and Zhejiang Province (see Figure 1.). It is one of the most developed regions in China. In recent years, water pollution of Lake Taihu is more and more serious because of the rapid development of the economy (Feng et al., 2007). And the pollution (especially eutrophication) has been attracted great attention.

In the East and Eastern Lakeshore of the lake, water quality is clear and remains stable in good condition. No cyanobacterial bloom has been found so far in these areas (Ma et al., 2006). But the chla concentration content of blue-green algae in the other part of Lake Taihu is high and variable. The spatial

\footnotetext{
* Correspond author: Qingjiu Tian, Professor in Nanjing University, China. Main research direction is Hyperspectral remote sensing
} 
distribution of chla concentration is non-uniform. So in this paper the other part of the lake was chosen as the study area.

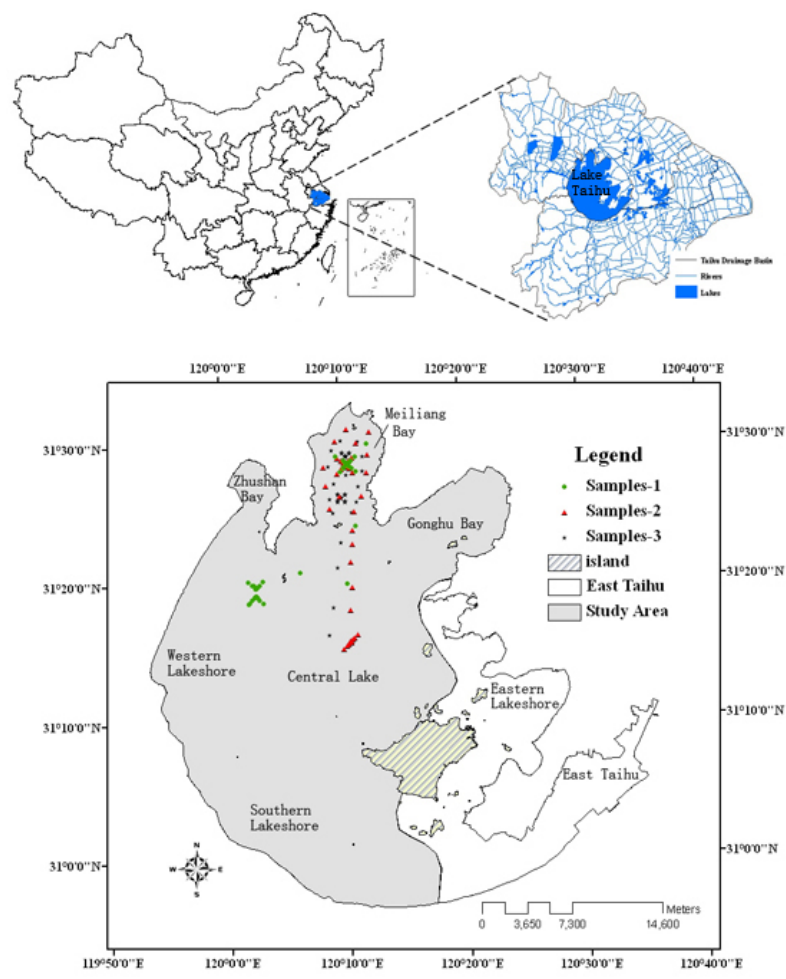

Figure 1. Study area and the location of sample points. The upper-right picture is the Lake drainage basin. Symbols in the right picture are sample points which were measured in October 2010, March 2011 and September 2011, respectively

\subsection{Field Measurements}

In this study, we undertook field surveys to get ground data in October 2010, March 2011 and September 2011 respectively. Sample points are typical and evenly distributed extend from Meiliang bay to central lake (See Figure 1.). Water sample and water spectral were collected at each sampling site, in which geographical coordinate was also recorded using GPS (measuring instrument: ASD FieldSpec HandHeld, the wavelength range 350-1050nm) (Feng et al., 2007). Meanwhile, water sample was refrigerated, and then token back to the laboratory to measure Chlorophyll a by means of spectrophotometric. Finally, 34 points, 45 points and 32 points were obtained for the following research after outliers removed.

\subsection{Image Data and Pre-processing}

HJ-1 CCD images and MODIS 1B (250m, 500m) were chosen as data sources.

HJ-1A, B (Environmental Satellite) were launched in 2008 in China. HJ-1A satellite carries CCD camera and Hyperspectral Imager, while $\mathrm{HJ}-1 \mathrm{~B}$ carries $\mathrm{CCD}$ and Infrared Multispectral cameras. All of the CCD cameras have four bands: $0.43-0.52 \mu \mathrm{m}$, $0.52-0.60 \mu \mathrm{m}, 0.63-0.69 \mu \mathrm{m}$, and $0.76-0.90 \mu \mathrm{m}$. And CCD sensors have a spatial resolution of $30 \mathrm{~m}$ and repetition cycle of them is two days (Jin et al., 2010). HJ-1 CCD images on October $31^{\text {st }}, 2010$, Mach $28^{\text {th }}$ and September $4^{\text {th }}, 2011$, were separately downloaded from China Centre for Resources
Satellite Data and Application. (C HJ-1 CCD Image Copyright 2010, 2011)

The data of MODIS (Moderate Resolution Images Spectroradiometer) has three different spatial resolutions: $250 \mathrm{~m}$, 500 , and $1000 \mathrm{~m}$. The image has a radio resolution of $12 \mathrm{bit}$ and the sensor passes over Lake Taihu every day (Hu et al., 2004). MODIS images $(250 \mathrm{~m}, 500 \mathrm{~m})$ on October $31^{\text {st }}, 2010$, Mach $28^{\text {th }}$ and September $4^{\text {th }}, 2011$, were separately downloaded from LAADS Web. (C MODIS Image Copyright 2010, 2011)

After obtaining those images, MODIS-Terra $(250 \mathrm{~m}$ and $500 \mathrm{~m})$ were first corrected with MRT. Next measured GCP were used to realize accurately geometric rectification of HJ-1 CCD and MODIS data. Then radiometric calibration and FlAASH atmospheric correction were performed on both HJ-1 CCD and MODIS-Terra. Finally reflectance images were calculated.

\section{METHODS}

\subsection{Estimation of Chla Concentration}

In order to obtain high correlation bands of chla concentrations and MODIS image, HJ-1 CCD image, ratio method, the difference method, and band combination algorithms were used to calculate the relevance (Wang et al., 2008). This article obtained MODIS image, HJ-1 CCD image of the reflectivity or reflectivity band combination based on latitude and longitude of the sample points. Then the correlation coefficients were calculated by chla and its reflectivity or reflectivity band combination. The results showed that the MODIS R1-R2, $\mathrm{R} 1 / \mathrm{R} 2,(\mathrm{R} 1-\mathrm{R} 2)$ / (R1 + R2) and HJ-1 H3-H4, H3/H4 had a high correlation with chla concentration. Therefore, these bands combinations were used to establish chla concentration empirical models (20 points for the model, and the rest for validation each time).

By comparing the average relative error of seasonal empirical model, H3-H4 of HJ-1 CCD image and R1-R2 of MODIS images was the best. Hence, the model would be established using H3-H4 and R1-R2.

\subsection{Semi-variance function}

Variograms is the quantitative description of the spatial variables correlation. It was mainly used for studying the correlation and spatial structure of area variables. (Zhang, 2008)

Chla concentration is interdependence and correlation among adjacent points, being a spatial structure. It is regionalized as random variable. Hence, variograms could be used to study the spatial heterogeneity of chla(Liu et al., 2002). In this study, semi-variance function was used to analyze the spatial structures and variation law of chla. The formula is (Curran et al., 1998):

$$
\gamma(h)=\frac{1}{2 N(h)} \sum_{i=1}^{N(h)}\left[Z\left(x_{i}\right)-Z\left(x_{i}+h\right)\right]^{2}
$$

where $\quad \gamma(h)=$ Semi-variance

$\mathrm{Z}(\mathrm{x})=$ Regional random variable

$\mathrm{h}=$ Sample interval

$\mathrm{N}(\mathrm{h})=$ Numbers of the sample with the distance of $\mathrm{h}$ 
Nugget $(\gamma 0)$, Still $(\gamma 0+\gamma)$, change range (a) are three important parameters of semi-variance function. Chla concentration is a region random variable. Nugget represents: when sampling interval h equals 0 , chla concentration is variation; nugget effect and the observed scale are closely linked. Still represents: the steady variograms value with distance enough. Change range represents: the reflection from the scale of chla concentration spatial autocorrelation. Under the change range, the closer points have lager correlation (Zhang, 2008).

\subsection{Modelling Spatial Scale Error}

According to the definitions of Distributed chla (chlaD) and Lumped chla (chlaL) (Bao et al., 2011), chlaD is the true value of the low resolution image while chlaL is the value which is estimated from low resolution image. In this study, chlaD and chlaL are given as following:

$$
\begin{aligned}
\text { chlaD } & =\frac{1}{n} \sum_{i=1}^{n} f\left(\rho_{i}\right) \\
\text { chlaL } & =f\left(\frac{1}{n} \sum_{i=1}^{n} \rho_{i}\right)
\end{aligned}
$$

And the estimation error between high resolution image and low resolution image is as below:

$$
\text { Error }=\frac{1}{n} \sum_{i=1}^{n} f\left(\rho_{i}\right)-f\left(\frac{1}{n} \sum_{i=1}^{n} \rho_{i}\right)
$$

where $\quad \mathrm{n}=$ Ratio of high resolution and low resolution $\rho=$ Difference reflectance of high resolution $f(\rho)=$ Estimation equation of chla concentration

Then the equation of estimation error is simplified by Taylor Formula as follows (Bao et al., 2011; Zhu et al., 2010):

$$
\begin{gathered}
\text { Error }=\frac{f^{\prime \prime}\left(\frac{1}{n} \sum_{i=1}^{n} \rho_{i}\right)}{2} D_{\rho} \\
\text { RelativeError }=\frac{\text { Error }}{\text { chlaD }}
\end{gathered}
$$

where $\quad f^{\prime \prime}(\rho)=$ Second order derivative of $f(\rho)$ $D_{\rho}=$ Variance of chla concentration in the window of $\mathrm{n} \times \mathrm{n}$.

\section{RESULTS AND DISCUSSION}

\subsection{Seasonal Spatial Distribution in Different Scales}

According to the scale error formula, the chla concentration estimate equation need to have the second order derivative. Through the comparison of the chla concentration estimate model, cubic polynomial function was used to calculate chla. And inversion of chla concentration in different seasons and different scales were shown as below (see Figure 2.- Figure 4.).

Figure 2, 3, 4 represented the spatial distribution maps about chla concentration on Mach 28th, 2011(spring), September 4th, 2011(summer) and October 31st, 2010(autumnr) in different scales of Lake Taihu. Firstly, the picture showed that chla concentration of Lake Taihu had uneven spatial distribution in different season from the figure. Generally speaking, the chla concentration was higher in the northwestward of Lake Taihu and shore, and lower in the south. Secondly, the chla concentration of Lake Taihu was lower in spring. The values centred on $0-35 \mu \mathrm{g} / \mathrm{L}$. The phenomenon of large area cyanobacteria agglomeration occurred in the summer and autumn. On September $4^{\text {th }}, 2011$ (summer), chla concentration varied in a wide range occurred in the west bank side of Lake Taihu, the outlet of Meiliang Bay and Gonghu Bay. The values centred on $1-120 \mu \mathrm{g} / \mathrm{L}$. Finally, by contrast the estimates of chla concentration under different data sources, the variation trend of spatial distribution map of chla concentration was similarity. But the inversion results, which were estimated from $\mathrm{HJ}$ satellite, had high spatial resolution and can better reflect the meticulous changes of the chla concentration, as shown in the red box of the figure.

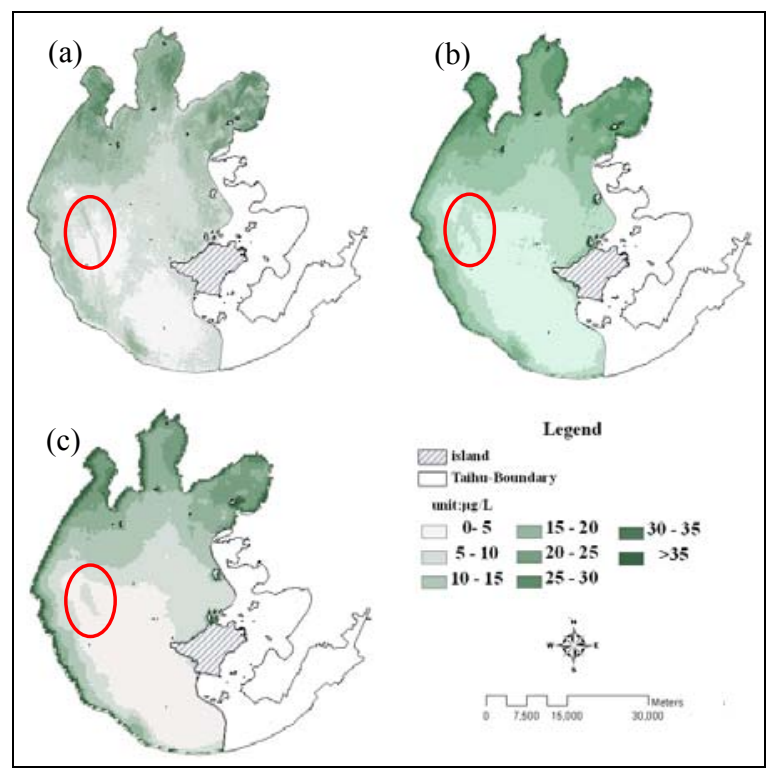

Figure 2. Comparison of chla concentration estimated from different scales on Mach $28^{\text {th }}, 2011$ (spring). (a)Chla concentration estimated from HJ-1 CCD (b) Chla concentration estimated from MODIS $250 \mathrm{~m}$ (c) Chla concentration estimated from MODIS $500 \mathrm{~m}$

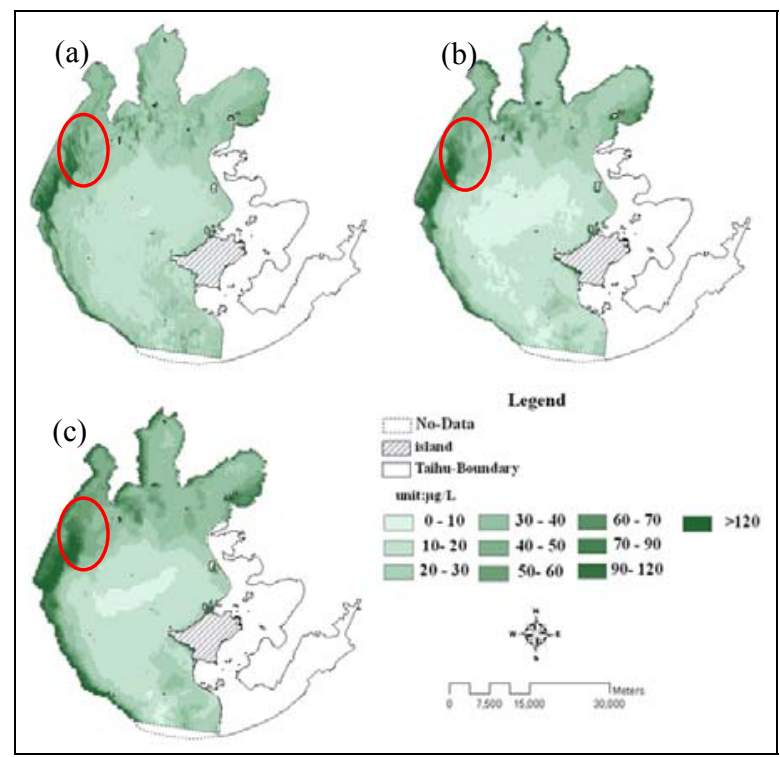


Figure 3. Comparison of chla concentration estimated from different scales on September $4^{\text {th }}, 2011$ (summer). (a)Chla concentration estimated from HJ-1 CCD (b) Chla concentration estimated from MODIS $250 \mathrm{~m}$ (c) Chla concentration estimated from MODIS $500 \mathrm{~m}$

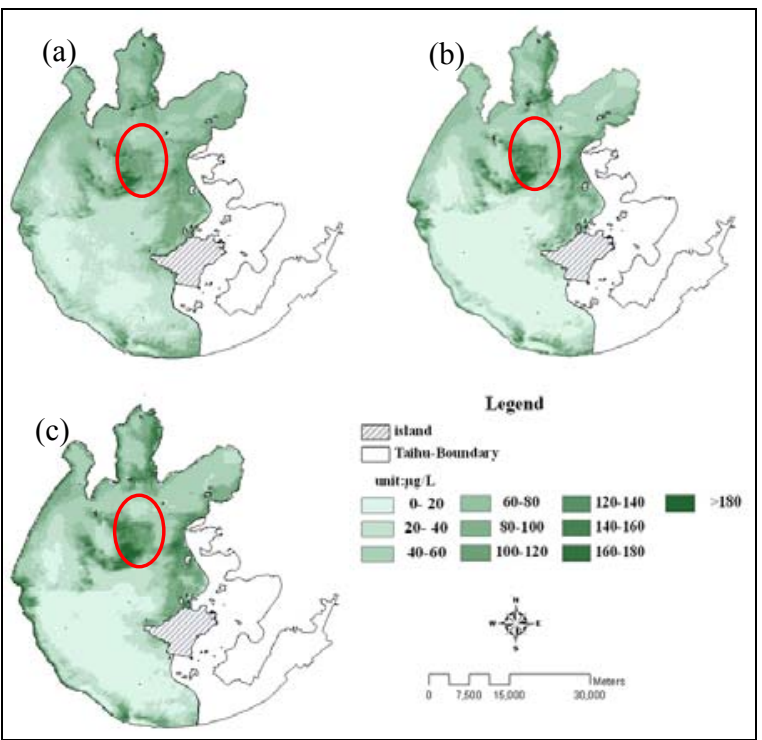

Figure 4. Comparison of chla concentration estimated from different scales on October $31^{\text {st }}, 2010$ (autumn). (a)Chla concentration estimated from $\mathrm{HJ}-1 \mathrm{CCD}$ (b) Chla concentration estimated from MODIS $250 \mathrm{~m}$ (c) Chla concentration estimated from MODIS $500 \mathrm{~m}$

From the results above, the spatial distribution of chla concentration had different trends in different seasons. Chla concentration is regional and seasonal. Because the upstream rivers of Lake Taihu in Jiangsu section are mainly in Meiliang Bay, Zhushan Bay, and west coast, and in Zhejiang section are mainly concentrated in the south coast of Lake Taihu. Water in Meiliang Bay and Zhushan Bay is relatively static. By the wind effect, cyanobacteria will accumulate in these areas (Xia et al., 2011; Sha et al., 2009). In recent years, the TN, TP of central lake region increased gradually to achieve the optimal growth conditions for cyanobacteria. This region was more suitable for the growth of cyanobacteria than the previous (Zhu, 2008). Therefore, in summer when cyanobacteria blooms were grew and in autumn when blooms were floating gathered, chla concentration was high in these regions. In addition, because of MODIS low spatial resolution, mixing phenomena of cyanobacteria and water, early warning detection accuracy cyanobacteria blooms was reducd.

\subsection{Analysis of Spatial Heterogeneity}

Method of field quadrats laid not only lack of sampling points and time-consuming, but also difficult to control the sampling time difference within a certain range (Xia et al., 2011). Thus, this article selected sample points from the inversion chla concentration image to study the spatial heterogeneity. $3 \mathrm{~km} \times$ $3 \mathrm{~km}$ of quadrats were selected in Meiliang Bay and Central Lake (measured data mainly in these two regions). The pixel values in the quadrat were seen as sample points which were normal distribution after logarithmic transformation (excluding outliers) . Then semi-variance values were respectively fitted to obtain parameters, such as Table 1., Table 2., Table 3.

\begin{tabular}{|cc|cccc|}
\hline \multicolumn{2}{|c|}{ Scale } & $\gamma 0$ & $\gamma 0+\gamma$ & $\mathrm{a}(\mathrm{m})$ & $\gamma /(\gamma 0+\gamma)$ \\
\hline \multirow{4}{*}{ Mei } & $30 \mathrm{~m}$ & $1.34 \mathrm{E}-02$ & $9.90 \mathrm{E}-02$ & 2563 & 0.865 \\
& $250 \mathrm{~m}$ & $8.00 \mathrm{E}-04$ & $6.80 \mathrm{E}-02$ & 3995 & 0.988 \\
& $500 \mathrm{~m}$ & $1.20 \mathrm{E}-04$ & $2.41 \mathrm{E}-02$ & 5110 & 0.995 \\
& $30 \mathrm{~m}$ & $1.14 \mathrm{E}-01$ & $4.68 \mathrm{E}-01$ & 4328 & 0.756 \\
Cen- & $250 \mathrm{~m}$ & $1.34 \mathrm{E}-03$ & $7.10 \mathrm{E}-03$ & 4026 & 0.811 \\
tral & & & & \\
& & & & \\
& & &
\end{tabular}

Table 1. Parameters of semi-variance in spring

\begin{tabular}{|c|c|c|c|c|c|}
\hline \multicolumn{2}{|c|}{ Scale } & $\gamma 0$ & $\gamma 0+\gamma$ & $a(m)$ & $\gamma /(\gamma 0+\gamma)$ \\
\hline \multirow{3}{*}{ Mei } & $30 \mathrm{~m}$ & $1.58 \mathrm{E}-03$ & $9.76 \mathrm{E}-03$ & 1548 & 0.838 \\
\hline & $250 \mathrm{~m}$ & $1.80 \mathrm{E}-04$ & $1.20 \mathrm{E}-02$ & 1230 & 0.985 \\
\hline & $500 \mathrm{~m}$ & $3.30 \mathrm{E}-03$ & $5.01 \mathrm{E}-02$ & 4518 & 0.934 \\
\hline \multirow{3}{*}{$\begin{array}{c}\text { Cen- } \\
\text { tral }\end{array}$} & $30 \mathrm{~m}$ & $7.80 \mathrm{E}-03$ & $3.30 \mathrm{E}-02$ & 4387 & 0.764 \\
\hline & $250 \mathrm{~m}$ & $4.40 \mathrm{E}-03$ & $2.08 \mathrm{E}-01$ & 2722 & 0.979 \\
\hline & $500 \mathrm{~m}$ & $9.50 \mathrm{E}-03$ & $5.00 \mathrm{E}-02$ & 4705 & 0.810 \\
\hline
\end{tabular}

Table 2. Parameters of semi-variance in summer

\begin{tabular}{|cc|cccc|}
\hline \multicolumn{2}{|c|}{ Scale } & $\gamma 0$ & $\gamma 0+\gamma$ & $\mathrm{a}(\mathrm{m})$ & $\gamma /(\gamma 0+\gamma)$ \\
\hline \multirow{4}{*}{ Mei } & $30 \mathrm{~m}$ & $5.20 \mathrm{E}-03$ & 0.22 & 3213 & 0.976 \\
& $250 \mathrm{~m}$ & $2.80 \mathrm{E}-03$ & 0.21 & 2568 & 0.987 \\
& $500 \mathrm{~m}$ & $1.00 \mathrm{E}-04$ & 0.19 & 4728 & 0.999 \\
& $30 \mathrm{~m}$ & $3.30 \mathrm{E}-02$ & 1.21 & 2495 & 0.973 \\
Cen- & $250 \mathrm{~m}$ & $8.00 \mathrm{E}-03$ & 1.28 & 1880 & 0.994 \\
tral & & & & \\
& & &
\end{tabular}

Table 3. Parameters of semi-variance in autumn

It can be seen from the table that the ratio of nugget and still (1$\gamma /(\gamma 0+\gamma))$ were used to represent the spatial autocorrelation level of regional random variables. The value less than $25 \%$ indicated that the variable had a strong spatial correlation (Xia et al., 2011). From the table, $\gamma 0 /(\gamma 0+\gamma)$ of chla concentration was small in different resolutions, indicating that spatial heterogeneity of chla concentration was mainly caused by the structural factors, random factors played a secondary role. Chla concentration showed similar structural in different scales of the same season. In addition, the range of nugget and still changed strongly in different seasons, indicating that there were different structural of chla concentration in different seasons.

\subsection{Spatial Scale Error in Different Seasons}

In this paper different resolution remote sensing images were used to study the differences of spatial scale. In order to reduce error from parameters of different satellites, transit time and other uncertainties factors, MODIS $250 \mathrm{~m}, 500 \mathrm{~m}$ images were used to carry out scale error analysis. According to the formula (5), combined with estimation formula (MODIS $250 \mathrm{~m}$ of the formula) of chla concentration, scale errors were calculated, which caused by chla concentration inversion of coarse resolution in different seasons. 
According to the equation of estimation error, retrieval algorithm of MODIS $250 \mathrm{~m}$ should exist second order derivative. Then cubic polynomial model was chosen for estimating chla concentration after comparing correlation coefficient. And the scale relative error of low resolution images (MODIS 500m) in different seasons can be calculated by formula (6) and cubic polynomial formulas. As field measured data were distributed in the north and central of Taihu, the paper only discussed relative errors in these places (see Figure 5.).

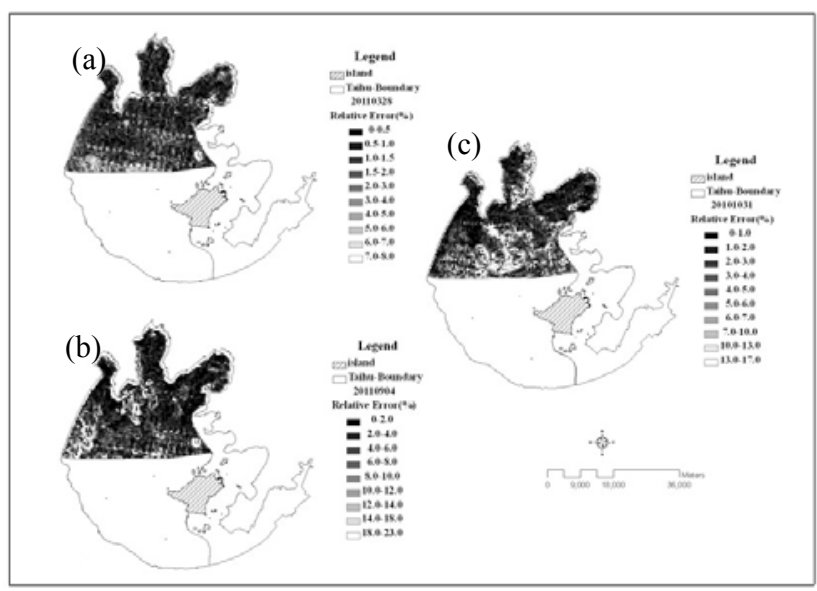

Figure 5. Comparison of relative errors in different season (MODIS 250m and MODIS 500m). (a) Relative error on Mach $28^{\text {th }}, 2011$ (spring). (b) Relative error on September $4^{\text {th }}, 2011$ (summer). (c) Relative error on October 31 $1^{\text {st }}, 2010$ (autumn)

Figure 5. showed the distribution of scale relative error of chla concentration in different seasons. In this paper effect of lake's boundary was ignored, and the results were as follows. In spring, the error was relatively lower and more homogeneous. The error concentrated between 0 and $4 \%$. The high values of relative errors were primarily concentrated in Meiliang Bay, Gonghu Bay and Western Lakeshore. The errors were higher and more unevenly distributed in summer. The scale relative error was high in Western Lakeshore and the area water between Meiliang Bay and Gonghu Bay, and the highest error reached to $23 \%$. The values were between $0-12 \%$ in other regions. Scale relative error was also high in autumn. The range of the relative error was $10 \%-17 \%$ in north of Meiliang Bay and central of Taihu. And it was $0-10 \%$ in other regions.

According to the paper above, the relative error of chla concentration varies with the seasons. Scale relative errors were lower and more evenly distributed in spring. Because of the low value, uniform spatial distribution of chla concentration and low variance of chla concentration, the relative scale errors were lower than that in summer and qutumn. For summer terms, the chla concentration was high and the spatial distribution was uneven, especially for the regions where accumulation of algal blooms (eg Meiliang Bay, Western Lakeshore). It also leaded to high variances, resulting high scale relative errors in these regions. In addition, it is noted that the scale relative error also closely related to the inversion model of chla concentration, and the results could affected by different inversion models.

\section{CONCLUSIONS}

Firstly, the paper established estimation models of chla concentration using HJ-1 CCD, MODIS 250m and MODIS
$500 \mathrm{~m}$ and field data in October 2010, March 2011, and September 2011. Secondly, spatial heterogeneity was studied using geostatistics. Thirdly, according to the spatial scale relative error model, scale errors of chla concentration which were inverted by MODIS $500 \mathrm{~m}$ were calculated in different seasons.

Chla concentration was variation in different seasons. The values were low and evenly distributed in spring. In summer, chla concentration was high in the west shore of Lake Taihu, export of Meiliang Bay and Gonghu Bay. And the high values mainly distributed in Meiliang Bay, Zhushan Bay and Gonghu Bay in autumn. In addition, the trends of chla concentration estimated from different scales were similar to each other in the same season. But details of low-resolution remote sensing images (especially blue-green cyanobacteria agglomeration area) couldn't be well express. Through the seasonal analysis of semi-variance function on different scales, it is known that structural factors caused by chla concentration were mainly due to spatial heterogeneity. Chla concentration at different scales showed similar structure in the same season, while the chla concentration in different seasons had different structural..

Lake Taihu is typical inland case II water. Higher spatial heterogeneity of chla concentration caused higher scale error. And the error changed with seasons. Scale errors were low and evenly distributed in spring. Because of exploding and floating together of cyanobacteria, scale errors increased up to $23 \%$. Moreover, great uncertainties and errors existed in the inversion of chla concentration using MODIS 500m data.

\section{REFERENCES}

Bao, Y., and Tian Q.J., 2011. Spatial scale effect and spatial scaling of chlorophyll-a concentration in Lake Taihu, China. In: International Conference on GeoInformatics, Shanghai, China, pp.1-5.

Chen, J., Ni, S. Y., Li, J. J. and Wu, T., 2006. Sealing effect and spatial variability in retrieval of vegetation LAl from remotely sensed data. Acta Ecological Sinica, 26(5), pp.15021508 .

Chen, J., Wang, W.C., Wang, B.J., and Wen Z.H., 2010.Distrubution variance of suspended sedment concentration and scaling effect correction: eight neighborhood algorithm. $J$. Infrared Millim. Waves, 29(6), pp. 440-444.

Curran, P.J., and Atkinson, P. M., 1998. Geostatistics and remote sensing. Progress in Physical Geography, 22, 61-78.

Fragoso, C.R., Motta, D.M.L., Collischonn, W., Tucci, C.E.M., and Nes, E.H.V., 2008. Modelling spatial heterogeneity of phytoplankton in Lake Mangueira, a large shallow subtropical lake in South Brazil. Ecological modeling, 219,pp.125-137.

Feng, W., Feng, X.Z., and Ma, R.H., 2007. Research on correlations between chlorophyll concentration and reflectance spectral of Taihu Lake. Remote Sensing Information, 1, pp. 1821.

Hu, C. M., Chen, Z. Q., Clayton, T. D., Swarzenski, P., Brock, J.C., and Muller-Karger, F. E., 2004. Assessment of estuarine water-quality indicators using MODIS medium resolution bands: 
initial results from Tampa Bay, FL. Remote Sensing of Environment, 93, pp. 423-441.

Jin, Y., Zhang, Y., Niu, Z.C., and Jiang, S., 2010. Application of Environmental Satellite HJ- 1 CCD Data for cyanobacteria bloom remote sensing in Taihu Lake. The Administration and Technique of Environmental Monitoring, 22(5), pp.53-56.

Liu, R. M., Wang, X. J. and Zheng, Y., 2002. The application of geostatistics in the study of water quality of Taihu Lake. Acta Scientiae Circumstantiae, 22(2), pp. 209-221.

Ma, R.H., Tang, J.W., and Dai, J.F., 2006. Bio-optical model Scalewith optimal parameter suiable for Taihu Lake in water colour remote sensing. International Journal of Remote Sensing, 27(19), pp.4305-4328.

Sha, H.M., Li, X.S., Yang, W.B., and Li, J.L., 2009. Aprimary study of blue algae bloom monitoring with MODIS remote sensing data in Taihu Lake. Transactions of Oceanology and Limnology, 3, pp.9-16.

Tang, S.K., and Ke C.Q., 2007. Monitoring of water quality parameters in Taihu Lake using Remote Sensing. Transactions of Oceanology and Limnology, 2, pp. 62-68.

Wang, S.X., Jiao, Y.Q., Zhou, Y., Zhu, L.Y, and Yan, F.L., 2008. Determination of Chlorophyll2a Concentration inTaihu Lake Using MODIS Image Data Based on Season Difference. Remote Sensing Information, 1, pp, 47-53.

Xia, R., Li, Y.M., Wu, C.Q., Jin, X., and Wang, Q., 2011. Spatial distribution and variation of concentration of suspended solids in Taihu Lake based on HJ -1 Satellite Data. Science Geographica Sinica, 31(2), pp. 197-203.

Zhang, J.X., 2008. Scale, uncertainty and Fusion of Spatial Information. Wuhan University Press, Wuchang, pp.87-90.

Zhang, Y.C., Lin, S., Qian, X., Wang, Q.G., Qian, Y., Liu, J.P., and Ge, Y., 2011. Temporal and spatial variability of chlorophyll a concentration in Lake Taihu using MODIS timeseries data. Hydrobiologia, 661(2), pp.235-250.

Zhang, Y.C., Qian, X., Shi, C.Z.Q., Lu, G.F., and Kong, F.X., 2009. Application of remote sensing on spatial-temporal distribution of chlorophyll-a in Taihu Lake. Environmental Protection Science, 36(1), pp. 105-108.

Zhou, G.H., Tang, .J.W., Tian, G.L., Li, J., and Liu, Q.H., 2009. Uncertainty analysis of inland water quality remote sensing: a review. Advances in Earth Science, 24(2), pp. 150-158.

Zhu, G.W., 2008. Eutrophic status and causing factors for a large, shallow and subtropical Lake Taihu, China. J. Lake Sci., 20(1), pp. 21-16.

Zhu, X.H., Feng, X.M., Zhao, y.s., and Song, X.N., 2010. Scale effect and error analysis of crop LAI inversion. Joural of Remote Sensing, 14(3), pp. 579-592.

\section{ACKNOWLEDGEMENTS}

This research is financially supported by national key basic research program project (Grant No. 2010CB434801) and
Research Fund for the Doctoral Program of Higher Education of China (Grant No. 20100091110012). 